\title{
Clinicoradiologic Correlations of Cerebral Microbleeds in Advanced Age
}

DI. Barnaure, (DM.-L. Montandon, (D) C. Rodriguez, DF. Herrmann, (DK.O. Lövblad, DP. Giannakopoulos, and DS. Haller

\section{ABSTRACT}

BACKGROUND AND PURPOSE: The presence of cerebral microbleeds has been associated with dementia and cognitive decline, although studies report conflicting results. Our aim was to determine the potential role of the presence and location of cerebral microbleeds in early stages of cognitive decline.

MATERIALS AND METHODS: Baseline 3T MR imaging examinations including SWI sequences of 328 cognitively intact communitydwelling controls and 72 subjects with mild cognitive impairment were analyzed with respect to the presence and distribution of cerebral microbleeds. A neuropsychological follow-up of controls was performed at 18 months post inclusion and identified cases with subtle cognitive deficits were referred to as controls with a deteriorating condition. Group differences in radiologic parameters were studied by using nonparametric tests, 1-way analysis of variance, and Spearman correlation coefficients.

RESULTS: Cerebral microbleed prevalence was similar in subjects with mild cognitive impairment and controls with stable and cognitively deteriorating conditions (25\%-31.9\%). In all diagnostic groups, lobar cerebral microbleeds were more common. They occurred in $20.1 \%$ of all cases compared with $6.5 \%$ of cases with deep cerebral microbleeds. None of the investigated variables (age, sex, microbleed number, location and depth, baseline Mini-Mental State Examination score, and the Fazekas score) were significantly associated with cognitive deterioration with the exception of education of $>12$ years showing a slight but significant protective effect $(\mathrm{OR}, 0.44 ; 95 \% \mathrm{Cl}, 0.22-0.92$; $P=.028$ ). The Mini-Mental State Examination and the Buschke total score were correlated with neither the total number nor lobar-versusdeep location of cerebral microbleeds.

CONCLUSIONS: Cerebral microbleed presence, location, and severity are not related to the early stages of cognitive decline in advanced age.

ABBREVIATIONS: $C D R=$ Clinical Dementia Rating scale; $C M B=$ cerebral microbleed; $\mathrm{dCON}=$ control with a deteriorating condition; sCON = control with a stable condition; $\mathrm{MCI}=$ mild cognitive impairment; MMSE = Mini-Mental State Examination

C erebral microbleeds (CMBs) are small, round, or ovoid lesions of the cerebral parenchyma of low signal intensity on T2* -weighted and susceptibility-weighted sequences, with a max-

Received March 15, 2016; accepted after revision August 15.

From the Division of Neuroradiology (I.B., K.O.L.), Department of Mental Health and Psychiatry (M.-L.M., C.R., P.G.), and Departments of Internal Medicine, Rehabilitation, and Geriatrics (F.H.), Geneva University Hospitals, Geneva, Switzerland; Affidea Centre de Diagnostique Radiologique de Carouge CDRC (S.H.), Geneva, Switzerland; Departments of Surgical Sciences and Radiology (S.H.), Uppsala University, Uppsala, Sweden; Department of Neuroradiology (S.H.), University Hospital Freiburg, Germany; and Faculty of Medicine (S.H.), University of Geneva, Geneva, Switzerland.

This study was partially funded by grants from the Swiss National Foundation (grant Nos. SNF 3200B0-1161193, SPUM 33CM30-124111).

Please address correspondence to Sven Haller, MD, MSc, Affidea Centre de Diagnostique Radiologique de Carouge CDRC, Clos de la Fonderie 1, 1227 Carouge, Switzerland; e-mail: sven.haller@me.com

-- Indicates open access to non-subscribers at www.ajnr.org

三 Indicates article with supplemental on-line appendix.

http://dx.doi.org/10.3174/ajnr.A4956 imal diameter of 5-10 mm, ${ }^{1}$ corresponding histologically to focal accumulations of hemosiderin-containing macrophages. ${ }^{2}$ They can be found in healthy subjects, their prevalence increasing with age, ${ }^{3-5}$ but are more frequent in patients with hypertensive encephalopathy and cerebral amyloid angiopathy. ${ }^{1,2}$ Microbleeds have been considered markers of small-vessel disease and are strongly associated with white matter hyperintensities. ${ }^{3,6,7}$ Both hypertensive small-vessel disease and cerebral amyloid angiopathy contribute to the formation of lobar CMBs, while CMBs located in the basal ganglia or infratentorial brain regions are mainly associated with hypertensive vasculopathy..$^{8-11}$

Their impact on cognition is still a matter of debate. Several studies supported a deleterious effect of CMBs, including increased prevalence in vascular dementia but also in Alzheimer disease, ${ }^{3,12-14}$ associations with poorer cognitive function in cross-sectional studies of patients with dementia, ${ }^{15}$ lower A $\beta 42$ levels in the CSF in Alzheimer disease and vascular dementia, ${ }^{16}$ 
and decreased frontal-executive performances at 5-year follow-up in patients with stroke. ${ }^{17}$ However, negative data were also reported with no or marginal impact of CMBs in early Alzheimer disease (for a review see van der Flier ${ }^{18}$ and Heringa et $\mathrm{al}^{19}$ ) and in subjects with subcortical vascular cognitive impairment $^{20}$ and symptomatic small-vessel disease. ${ }^{21}$

Data on mild cognitive impairment (MCI) are even more ambiguous. This entity was initially used to denote a functionally nondisabling amnestic disorder, but its definition has been recently expanded to include any form of cognitive problem that may increase the risk of clinically overt dementia. Certain studies postulated that CMBs are significantly associated with both MCI and the risk of conversion to Alzheimer disease (for a review see Loitfelder et $\mathrm{al}^{8}$ and Lei et $\mathrm{al}^{22}$ ). Other authors reported a significant association between amyloid deposition and lobar CMB occurrence in patients with MCI but without any relationship between their presence and early cognitive decline. ${ }^{23}$ Similarly, substantial formation of lobar but not deep and infratentorial microbleeds was associated with worse cognition in the Rotterdam Scan Study. ${ }^{24}$ The latter is a population-based study on agerelated changes on brain MR imaging. Cross-sectional analysis of 3979 individuals without dementia from this cohort revealed that subjects with higher numbers of lobar microbleeds performed worse in tests exploring various cognitive domains, even after adjustments for vascular risk factors and brain atrophy. ${ }^{24}$

Most of the previous studies concerned cross-sectional casecontrol comparisons and did not explore whether CMBs may predict very early phases of cognitive deterioration in healthy controls. Furthermore, the location of CMBs that may be associated with the disruption of brain networks was rarely taken into account. ${ }^{19}$ The current investigation is based on the assumption that if CMBs reflect structural damage, their location should have an impact on the corresponding function affected. To determine the potential role of CMBs in early stages of cognitive decline before MCI, we evaluated both the number and location of CMBs in a large sample of 328 community-dwelling healthy controls who were cognitively intact. Imaging was performed at baseline, and cognitive status was determined on the basis of extensive neuropsychological testing both at baseline and at 18-month follow-up. The results were compared with a group of 72 fully documented patients with MCI recruited in the same geographic area.

\section{MATERIALS AND METHODS \\ Participants}

Participants were contacted via advertisements in local media to guarantee a community-based sample. After detailed information about the research was provided, telephone screening was performed with the following inclusion criteria: normal or correctedto-normal visual acuity; no history of major medical disorders (neoplasm, cardiovascular disorders, infectious diseases), sustained head injury, or psychiatric or neurologic disorders; no alcohol or drug abuse; and no regular use of neuroleptics, antidepressants, mood stabilizers, anticonvulsant drugs, or psychostimulants. To control for the confounding effect of cerebrovascular diseases, we did not include patients with subtle cardiovascular symptoms, severe hypertension, and a history of stroke or transient ischemic episodes in the present study. Mild hypertension was present at baseline in $27 \%$ of the entire sample. The local ethics committee approved this prospective study, and all participants gave written informed consent before inclusion. The inclusion period for controls and those with MCI was from October 2010 to January 2011, when the present cohort was established in the context of a federally funded research project for identifying functional imaging and electroencephalography markers predicting subtle cognitive deficits in a communitydwelling sample of healthy controls. A relatively small number of patients with MCI were recruited as an additional control group.

\section{Neuropsychological Assessment}

All participants underwent extensive neuropsychological testing, as described in detail in the On-line Appendix. Briefly, all participants underwent neuropsychological testing and MR imaging at baseline. Participants classified as controls at baseline additionally underwent neuropsychological testing at 18-month follow-up. Those whose cognitive scores remained unchanged were classified as controls with a stable condition ( $\mathrm{sCON})$. Those whose performance at follow-up was at least 0.5 SDs lower compared with the first evaluation on at least 2 cognitive tests were classified as controls with a deteriorating condition $(\mathrm{dCON})$. All individuals were also evaluated with the Clinical Dementia Rating scale (CDR). ${ }^{25}$ Only those with a CDR score of 0 and scores within 1.5 SDs of the age-appropriate mean in all other tests were included in the control group. In agreement with the Petersen criteria, ${ }^{26}$ participants having a CDR score of 0.5 but no dementia and a score exceeding 1.5 SDs below the age-appropriate mean in any of the above tests were confirmed as to their MCI status.

Two neuropsychologists clinically assessed all individuals independently with high interrater agreement $(\kappa=0.92)$. The final classification of $\mathrm{sCON}$ versus dCON was made by a trained neuropsychologist, who took into account both the neuropsychological test results and overall clinical assessment. ${ }^{27}$

\section{MR Imaging}

MR imaging was performed with a routine 3T scanner (Magnetom Trio; Siemens, Erlangen, Germany) and included a standard susceptibility-weighted sequence (matrix, $192 \times 256 \times 128$; voxel size, $0.98 \times 0.98 \times 1.1 \mathrm{~mm}$; TE/TR, 20/28 ms; number of signals acquired, 1; flip angle, $15^{\circ}$; parallel imaging factor, 2 ; acquisition time, 6 minutes 1 second). In addition, standard DTI, T2weighted, T1-weighted, and fluid-attenuated inversion recovery sequences were performed and analyzed to exclude anomalies such as ischemic lesions, parenchymal macrobleeds, extra-axial hematomas, or space-occupying lesions.

\section{Image Analysis}

Cerebral microbleeds were defined as focal areas $(<10 \mathrm{~mm})$ of very low signal intensity. Two independent readers ( 1 board-certified neuroradiologist and 1 trained neuropsychologist with 7 and 3 years of experience, respectively) analyzed SWI to define the presence, number, and location of CMBs. In cases of discordant findings, a senior third reader (a board-certified neuroradiologist with 16 years of experience) reviewed the images and determined 


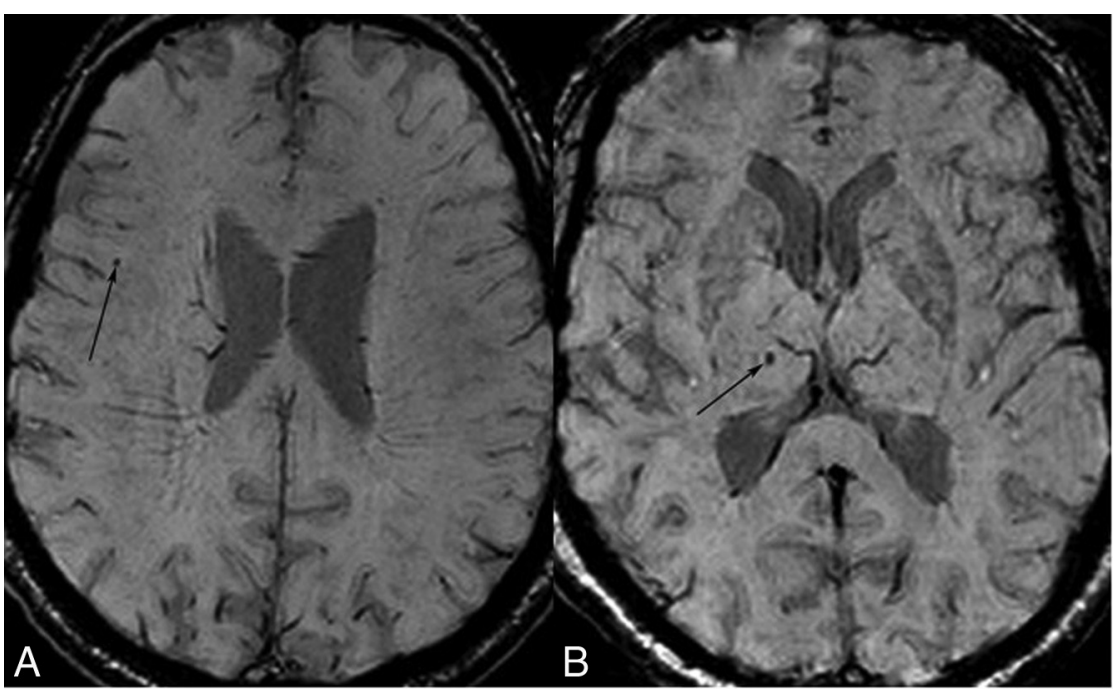

FIGURE. Cerebral microbleeds. Axial SWI of 2 subjects. A, Lobar CMB. Right inferior frontal CMB (arrow) close to the corticomedullary junction. B, Right thalamic CMB (arrow).

Table 1: Demographic data for sCON, dCON, and $\mathrm{MCl}$

\begin{tabular}{ccccc}
\hline & sCON $(\boldsymbol{n}=152)$ & dCON $(\boldsymbol{n}=176)$ & $\mathbf{M C I}(\boldsymbol{n}=\mathbf{7 2})$ & $\boldsymbol{P}$ Value \\
\hline Females (\%) & $93(61.2)$ & $111(63.1)$ & $25(34.7)$ & $<.001$ \\
Age (M, SD) & $73.8(3.9)$ & $74.5(4.1)$ & $74(6.2)$ & .372 \\
Education $^{\mathrm{a}}$ & & & & .070 \\
$<9(\%)$ & $24(15.8)$ & $31(17.6)$ & $8(11.1)$ & \\
$9-12(\%)$ & $62(40.8)$ & $93(52.8)$ & $37(51.4)$ & \\
$>12(\%)$ & $66(43.4)$ & $52(29.6)$ & $27(37.5)$ & \\
\hline
\end{tabular}

Note:- $M$ indicates mean.

${ }^{a}$ Education in years of schooling.

the final rating. CMB "mimics" such as signal voids caused by vessels or basal ganglia calcification were excluded.

CMBs were classified according to 2 different categories (Figure): lobar versus deep (including the basal ganglia, thalamus, deep white matter, and infratentorial structures) and with further classification of lobar microbleeds according to the cerebral lobe involved (frontal, parietal, temporal, or occipital).

In addition to the analysis of CMBs, microvascular burden in the form of white matter lesions was analyzed on T2-/FLAIRweighted images according to the established Fazekas scale. ${ }^{28}$

\section{Statistical Analysis}

$\chi^{2}$ tests, Kruskal-Wallis nonparametric tests, and 1-way ANOVA were used to compare binary/nominal, ordinal, and continuous Gaussian variables, respectively, among the 3 groups. The Cuzick nonparametric test for trend across ordered groups was used to compare the lobar distribution of microbleeds. A $t$ test and the Mann-Whitney $U$ test were applied to compare ordinal and continuous variables between 2 groups. Moreover, the number and location of CMBs were correlated with neuropsychological data at baseline by using the Spearman rank correlation. A multiple logistic regression model was built with $\mathrm{sCON} / \mathrm{dCON}$ distinction as the dependent variable and age, sex, CMB location and depth, baseline Mini-Mental State Examination (MMSE) score, education, and Fazekas scale score as independent variables.

A multiple linear regression model was built to determine whether CMBs predict longitudinal changes in cognitive scores. Because cognitive performances at follow-up are expressed on different scales, which are often discrete, they cannot be linearly combined by adding the individual scores to a unique composite cognitive score. We converted all results to $z$ scores; then, we summed the number of cognitive tests at follow-up with performances at least 0.5 SDs higher compared with the first evaluation, leading to the number of tests with improved performances (range, 0-14). Similarly, we summed the number of cognitive tests at follow-up with performances at least 0.5 SDs lower compared with the first evaluation, leading to the number of tests with decreased performances (range, 0-14). Finally, we computed the number of tests with improved minus the number of tests with decreased performances to obtain a continuous cognitive score and built a multiple linear regression model with this score as the dependent variable and age, sex, CMB location and depth, baseline MMSE score, education, and Fazekas scale score as independent variables.

All statistics were performed by using the STATA statistical software, Version 14.1 (StataCorp, College Station, Texas).

\section{RESULTS}

\section{Demographic Data}

Demographic data of the cohort are shown in Table 1 . There were no significant differences among the 3 groups ( $\mathrm{sCON}$, dCON, and $\mathrm{MCI}$ ) regarding age (the mean age was 74 years) and education level. However, a significant difference was evident for sex with a male predominance in the MCI group $(P<.001)$.

\section{Neuropsychological Data}

Neuropsychological data are presented in Table 2. As expected, there were group differences at follow-up, with worse cognitive performances of $\mathrm{dCON}$ for the Shapes test (3 immediate recalls $[P=.004]$ and delayed recall $[P=.024])$, Digit Symbol Coding $(P<.001)$, and ideomotor transitive praxis $(P=.008)$. The Shapes test assesses visual memory (immediate and delayed) via the reproduction of simple designs. Digit Symbol Coding (timemonitored copy of symbols) explores perceptual-motor speed mostly related to attention. Ideomotor transitive praxis refers to the ability to perform transitive movements demonstrating the use of tools.

\section{Number of CMBs}

Eleven subjects were excluded due to a presumed (incidental) diagnosis of amyloid angiopathy (based on the observation of multiple microbleeds at the corticomedullary junction in association with signs of superficial siderosis or sequelae of lobar hemorrhage) or hypertensive encephalopathy (based on the observation of microbleeds in association with extensive white matter signal anomalies and infarctions).

Most subjects had no CMBs: $75.0 \%$ of sCON, $72.7 \%$ of dCON, 
Table 2: Neuropsychological data of control subjects

\begin{tabular}{|c|c|c|c|c|c|}
\hline & \multicolumn{2}{|c|}{$\begin{array}{c}\text { sCON } \\
(n=152)\end{array}$} & \multicolumn{2}{|c|}{$\begin{array}{l}\text { dCON } \\
(n=176)\end{array}$} & \multirow{2}{*}{$\begin{array}{c}P \\
\text { Value }\end{array}$} \\
\hline & M & SD & M & SD & \\
\hline MMSE & 28.6 & 1.2 & 28.4 & 1.5 & .439 \\
\hline IADL & 8.3 & 0.82 & 8.3 & 1.1 & .933 \\
\hline HADS total & 5.7 & 3.5 & 6.2 & 3.9 & 1.000 \\
\hline Anxiety & 4.3 & 2.6 & 4.5 & 2.7 & 1.000 \\
\hline Depression & 1.4 & 1.6 & 1.8 & 1.9 & .248 \\
\hline Digit Span Forward & 5.6 & 1.1 & 5.8 & 0.96 & .386 \\
\hline $\begin{array}{l}\text { Visual Memory Span Forward } \\
\text { (Corsi) }\end{array}$ & 5.1 & 0.97 & 5.1 & 0.89 & .876 \\
\hline $\begin{array}{l}\text { RI-48 Cued Recall Test } \\
\text { Delayed cued recall }\end{array}$ & 27.3 & 5.0 & 26.8 & 5.1 & 1.000 \\
\hline $\begin{array}{l}\text { Shapes test } \\
\text { Total score ( } 3 \text { immediate } \\
\text { recalls) }\end{array}$ & 33.9 & 3.2 & 32.7 & 4.3 & $.004^{\mathrm{a}}$ \\
\hline Delayed recall & 11.7 & 0.74 & 11.4 & 1.3 & $.024^{\mathrm{a}}$ \\
\hline Boston Naming Test & 19.3 & 1.0 & 19.2 & 1.2 & .680 \\
\hline Digit Symbol Coding & 56.1 & 11.8 & 50.8 & 11.0 & $<.001^{\mathrm{a}}$ \\
\hline $\begin{array}{l}\text { Trail-Making Test A } \\
\text { Time (s) }\end{array}$ & 42.1 & 16.0 & 42.0 & 11.4 & 1.000 \\
\hline $\begin{array}{l}\text { Error } \\
\text { Trail-Making Test B }\end{array}$ & 0.05 & 0.25 & 0.07 & 0.31 & 1.000 \\
\hline Time (s) & 98.7 & 41.9 & 105.7 & 43.0 & .667 \\
\hline Error & 0.51 & 0.73 & 0.48 & 0.75 & 1.000 \\
\hline $\begin{array}{l}\text { Verbal Fluency } \\
\text { Wisconsin Card Sorting Test }\end{array}$ & 22.0 & 5.6 & 22.5 & 6.5 & 1.000 \\
\hline $\begin{array}{l}\text { No. of categories completed } \\
\text { Praxis }\end{array}$ & 4.6 & 2.1 & 4.3 & 2.2 & .223 \\
\hline Constructional & 10.9 & 0.48 & 10.7 & 0.77 & .032 \\
\hline Ideomotor transitive & 9.4 & 0.81 & 9.1 & 1.2 & $.008^{\mathrm{a}}$ \\
\hline Ideomotor intransitive & 19.5 & 1.1 & 19.5 & 1.0 & .686 \\
\hline Reflexive & 7.0 & 0.98 & 6.9 & 1.1 & .665 \\
\hline $\begin{array}{l}\text { Visual gnosis (Ghent Overlapping } \\
\text { Figures) }\end{array}$ & 5.0 & 0.08 & 5.0 & 0.08 & .917 \\
\hline
\end{tabular}

Note:-IADL indicates Lawton Instrumental Activities of Daily Living scale; HADS, Hospital Anxiety and Depression Scale; M, mean.

a Significant.

Table 3: Microbleed numbers in the present series ${ }^{\mathrm{a}}$

\begin{tabular}{|c|c|c|c|c|c|c|}
\hline \multirow[b]{2}{*}{ Microbleeds } & \multicolumn{2}{|c|}{$\begin{array}{c}\text { sCON } \\
(n=152)\end{array}$} & \multicolumn{2}{|c|}{$\begin{array}{c}\text { dCON } \\
(n=176)\end{array}$} & \multicolumn{2}{|c|}{$\begin{array}{c}\mathrm{MCl} \\
(n=72)\end{array}$} \\
\hline & No. & $\%$ & No. & $\%$ & No. & $\%$ \\
\hline 0 & 114 & 75.0 & 128 & 72.7 & 49 & 68.1 \\
\hline 1 & $25(25)$ & 16.5 & $30(30)$ & 17.1 & $21(21)$ & 29.2 \\
\hline 2 & 9 (18) & 5.9 & $12(24)$ & 6.8 & $2(4)$ & 2.8 \\
\hline 3 & $3(9)$ & 2.0 & 6 (18) & 3.4 & $0(0)$ & 0.00 \\
\hline 4 & $1(4)$ & 0.66 & $0(0)$ & 0.00 & $0(0)$ & 0.00 \\
\hline Total $^{\mathrm{b}}$ & $152(56)$ & 100 & 176 (72) & 100 & $72(25)$ & 100 \\
\hline
\end{tabular}

${ }^{a}$ Number and proportion of subjects with $x$ numbers of $C M B$ in each group. Number of $\mathrm{CMBs}$ is in parentheses.

${ }^{\mathrm{b}}$ The total number of microbleeds for the 3 groups was 153 .

and $68.1 \%$ of MCI. Although the prevalence of at least $1 \mathrm{CMB}$ increased from $25.0 \%$ in those with sCON to $28.3 \%$ in those with $\mathrm{dCON}$ and $31.9 \%$ in patients with MCI, group differences were not significant. There was no significant difference in the number of CMBs among the 3 groups (Table 3 ).

\section{Location of CMBs}

Lobar versus Deep. Overall, lobar CMBs were more common and occurred in $20.1 \%$ of all cases compared with only $6.5 \%$ of cases with deep CMBs. There was no significant difference in the number of cases with lobar or deep CMBs among the 3 groups (Table 4).

Lobar Distribution. There was no lobar predilection specific to 1
Table 4: Microbleed distribution ${ }^{\mathrm{a}}$

\begin{tabular}{|c|c|c|c|c|c|c|}
\hline \multirow[b]{2}{*}{ Microbleed } & \multicolumn{2}{|c|}{$\begin{array}{c}s C O N \\
(n=152)\end{array}$} & \multicolumn{2}{|c|}{$\begin{array}{c}\text { dCON } \\
(n=176)\end{array}$} & \multicolumn{2}{|c|}{$\begin{array}{c}\mathrm{MCl} \\
(n=72)\end{array}$} \\
\hline & No. & $\%$ & No. & $\%$ & No. & $\%$ \\
\hline \multicolumn{7}{|l|}{ Location } \\
\hline None & 114 & 75.0 & 128 & 72.7 & 49 & 68.1 \\
\hline Lobar & 31 & 20.4 & 34 & 19.3 & 18 & 25.0 \\
\hline Deep & 7 & 4.6 & 14 & 8.0 & 5 & 6.9 \\
\hline \multicolumn{7}{|l|}{ Lobes } \\
\hline Frontal & 17 & 11.2 & 19 & 10.8 & 9 & 12.5 \\
\hline Parietal & 5 & 3.3 & 11 & 6.3 & 5 & 6.9 \\
\hline Temporal & 5 & 3.3 & 6 & 3.4 & 3 & 4.2 \\
\hline Occipital $^{b}$ & 15 & 9.9 & 9 & 5.1 & 2 & 2.8 \\
\hline
\end{tabular}

${ }^{a}$ Number and proportion of subjects with $\mathrm{CMBs}$ for each location.

${ }^{\mathrm{b}} \mathrm{P}=.03$ (between $\mathrm{sCON}$ and $\mathrm{MCI}$ ).

Table 5: Multivariate logistic regression to predict progression (sCON/dCON distinction)

\begin{tabular}{llcc}
\hline & OR & 95\% CI & $P$ Value \\
\hline Male & 1.11 & $(0.68-1.81)$ & .687 \\
Age (yr) & 1.03 & $(0.97-1.10)$ & .289 \\
MMSE & 0.89 & $(0.74-1.07)$ & .216 \\
Education (yr) & & & \\
$\quad<9$ & 1.00 & - & - \\
$\quad 9-12$ & 0.76 & $(0.38-1.50)$ & .427 \\
$\quad>12$ & 0.44 & $(0.22-0.92)$ & .028 \\
Fazekas score & & & \\
$\quad$ Absent & 1.00 & - & - \\
$\quad$ Mild & 0.69 & $(0.41-1.18)$ & .176 \\
$\quad$ Moderate & 0.50 & $(0.24-1.04)$ & .062 \\
$\quad$ Severe & 1.30 & $(0.51-3.31)$ & .586 \\
No. of microbleeds & 2.14 & $(0.70-6.48)$ & .180 \\
Microbleed lobar location & & & \\
$\quad$ Frontal & 0.41 & $(0.07-2.58)$ & .343 \\
$\quad$ Parietal & 1.18 & $(0.22-6.17)$ & .847 \\
$\quad$ Temporal & 0.63 & $(0.08-5.13)$ & .667 \\
$\quad$ Occipital & 0.26 & $(0.05-1.28)$ & .098 \\
$\quad$ Other & 8.09 & $(0.73-89.20)$ & .088 \\
Microbleed depth & & & \\
$\quad$ Absent & 1.00 & - & - \\
$\quad$ Lobar & 0.85 & $(0.21-3.46)$ & .825 \\
$\quad$ At least 1 deep & 0.18 & $(0.02-2.09)$ & .171 \\
\hline
\end{tabular}

group. The highest prevalence of CMBs was found in the frontal lobe ( $11.3 \%$ of subjects having frontal lobe CMBs), followed by the occipital, parietal, and temporal lobes $(6.5 \%, 5.3 \%$, and 3.5\%, respectively). There was no significant difference in the percentage of cases with CMBs among the 3 groups for any of these lobes, with the exception of the occipital lobe. The groups with more cognitive deficits had significantly fewer occipital lesions than those in the sCON group ( $P$ for trend $=.0261$ ) (Table 4 ).

\section{Correlation of CMBs with Neurocognitive Testing}

There was no significant correlation between the scores of the neurocognitive testing and the number or location of CMBs. For instance, the MMSE and the Buschke total score were correlated with neither the total number (Spearman $\rho=-0.023, P=.653$; $\rho=-0.065 ; P=.213$, respectively) nor the lobar-versus-deep location of CMBs (Spearman $\rho=-0.013, P=.790 ; \rho=-0.064$, $P=.219$, respectively). This finding was also the case for lobar distribution (data not shown).

A multiple logistic regression model (Table 5) showed that none of the investigated variables (age, sex, CMB number, loca- 


\begin{tabular}{|c|c|c|c|}
\hline & Coefficient & $95 \% \mathrm{Cl}$ & $P$ Value \\
\hline Male & -0.39 & $(-1.29-0.51)$ & .391 \\
\hline Age (yr) & -0.06 & $(-0.18-0.05)$ & .260 \\
\hline MMSE & -0.35 & $(-0.68-0.01)$ & .042 \\
\hline \multicolumn{4}{|l|}{ Education (yr) } \\
\hline$<9$ & 1.00 & - & - \\
\hline $9-12$ & 0.21 & $(-1.02-1.44)$ & .739 \\
\hline$>12$ & 0.76 & $(-0.54-2.07)$ & .252 \\
\hline \multicolumn{4}{|l|}{ Fazekas score } \\
\hline Absent & 1.00 & - & - \\
\hline Mild & 0.57 & $(-0.40-1.55)$ & .247 \\
\hline Moderate & 0.71 & $(-0.63-2.05)$ & .298 \\
\hline Severe & 0.18 & $(-1.44-1.81)$ & .826 \\
\hline No. of microbleeds & -0.36 & $(-2.27-1.54)$ & .707 \\
\hline \multicolumn{4}{|c|}{ Microbleed lobar location } \\
\hline Frontal & 0.58 & $(-2.56-3.72)$ & .716 \\
\hline Parietal & -0.89 & $(-3.81-2.02)$ & .546 \\
\hline Temporal & 0.80 & $(-2.91-4.50)$ & .672 \\
\hline Occipital & 1.78 & $(-0.98-4.55)$ & .205 \\
\hline Other & -2.01 & $(-6.12-2.09)$ & .336 \\
\hline \multicolumn{4}{|l|}{ Microbleed depth } \\
\hline Absent & 1.00 & - & - \\
\hline Lobar & -1.39 & $(-3.93-1.16)$ & .284 \\
\hline At least 1 deep & 1.11 & $(-3.18-5.40)$ & .612 \\
\hline
\end{tabular}

tion and depth, baseline MMSE score, and Fazekas score) were significantly associated with deterioration among controls as expressed by the dCON status, with the exception of education of $>12$ years showing a slight-but-significant protective effect (OR, $0.44 ; 95 \%$ CI, 0.22-0.92; $P=.028)$.

Overall, $26 \%$ of the sample had a resulting decline in $\geq 2$ cognitive tests when simultaneously taking into account both improved and decreased performances in the 14 cognitive tests. A multiple linear regression model (Table 6) predicting the number of cognitive tests $(n=14)$ with improved minus the number of tests with decreased performances by more than 0.5 SDs showed no effect of microbleeds and a protective effect of the MMSE score (coefficient, $-0.35 ; 95 \% \mathrm{CI},-0.68-0.01$; $P=.042)$.

\section{DISCUSSION}

The current longitudinal, community-based study addresses the impact of CMBs in the very early stage of cognitive decline. We performed imaging at baseline in 328 elderly individuals with intact cognition at inclusion and determined very early cognitive decline based on neuropsychological follow-up at 18 months. Moreover, we compared these results with a group of 72 patients with fully documented MCI. We found no significant differences in the number or location of CMBs between controls with stable and deteriorating conditions and those with MCI. Moreover, there was no significant association between the number or location of CMBs and neuropsychological testing.

\section{Prevalence of CMBs}

Overall, the prevalence of CMBs in the present series varied from $25.0 \%$ in sCON to $28.3 \%$ in $\mathrm{dCON}$ and $31.9 \%$ in MCI. The trend toward increasing prevalence in MCI cases was not significant.

The prevalence in healthy controls $(25.0 \%-28.3 \%)$ was higher than that reported in earlier studies. ${ }^{4,24,29}$ In particular, the Rotterdam Scan study that focused on elderly controls found a CMB prevalence of $15.3 \%{ }^{4,24}$ Differences in inclusion criteria and imaging techniques may be at the origin of these differences. Notably, our series included elderly individuals with a mean age of 74 years, clearly higher than that in previous reports. Because the prevalence of CMBs increases with age,$^{3-5}$ the higher age may partially explain the increased CMB prevalence observed here. In addition, technical differences among the studies, namely examinations at different field strengths ( $3 \mathrm{~T}$ versus $1.5 \mathrm{~T}$ ) and with different sequences (SWI versus $\mathrm{T}^{\star}$ gradient echo) may contribute to differing results. The present study used an SWI sequence obtained at $3 \mathrm{~T}$, while previous reports in controls used $1.5 \mathrm{~T}$ machines and/or $\mathrm{T} 2^{\star}$ sequences. It has been shown that SWI sequences detect more CMBs than 2D gradient-recalled echo sequences, ${ }^{30-32}$ with an increase in detected lesions of $67 \%$ according to Nandigam et al. ${ }^{30}$

As in our study, the prevalence of CMBs was relatively similar in patients with $\mathrm{MCI}$ and controls ( $14 \%$ and $11 \%$, respectively) in the cohort of Ayaz et al, ${ }^{33}$ including 28 healthy controls and 75 subjects with $\mathrm{MCI}$ examined at $1.5 \mathrm{~T}$ with a SWI sequence. Other studies found an association between CMBs and low cognitive performance ${ }^{12}$ or cognitive decline. ${ }^{13}$ This variability may be due to differences in study design with varying cohort sizes and composition (eg, absence of a control group, varying exclusion criteria) and variable definitions of cognitive impairment. In the present study, the control group at baseline included only subjects who were cognitively intact confirmed by extensive neuropsychological testing. Moreover, subjects with a presumed (incidental) diagnosis of amyloid angiopathy or hypertensive encephalopathy were excluded to eliminate confounding effects.

\section{CMB-Related Variables in the 3 Diagnostic Groups}

The location of CMBs (ie, lobar versus deep and according to cerebral lobes) was not different among the 3 groups in our study with the exception of occipital lobe location. In the present series, subjects with MCI had a strikingly low prevalence of CMBs in the occipital cortex compared with sCON ( $P$ for trend $=.0261$ ). This latter group showed a similar CMB prevalence in frontal (comparable to $\mathrm{MCI}$ ) and occipital cortices, excluding the idea of a preferential $\mathrm{CMB}$ formation in the visual cortex. Although unclear from a physiologic viewpoint, this finding further points to the dissociation between the formation of these lesions and cognitive decline.

In contrast, previous reports showed a strong association of $\mathrm{CMB}$ location with performance on cognitive tasks both in crosssectional and longitudinal studies, though with conflicting results. Qiu et al ${ }^{12}$ found that deep hemispheric and infratentorial CMBs were associated with low performance, while in the Rotterdam Scan Study, strictly lobar CMB had the strongest impact on cognition. ${ }^{24}$ In a longitudinal study by Miwa et al, ${ }^{34}$ multiple CMBs or the presence of both deep and lobar CMBs (but not only strictly lobar $\mathrm{CMBs}$ ) was associated with an increased risk for dementia, whereas Chiang et $\mathrm{al}^{35}$ found that lobar CMBs were associated with accelerated cognitive decline in their cohort. One could speculate that because CMBs reflect structural damage in a given region, their formation locally may affect the corresponding 
cognitive functions (eg, executive impairment in a frontal location). This was clearly not the case in the present series.

In fact, $\mathrm{CMB}$ presence and number did not correlate with neuropsychological variables in our cohort.

\section{CMB-Based Prediction of Cognitive Decline in Healthy Elderly}

In previous studies, greater or increasing numbers of CMBs with time were related to impaired cognitive functioning, in both cross-sectional $^{12,24}$ and longitudinal analyses ${ }^{13,33-36}$ in different types of cohorts (eg, population-based or in a memory clinic setting). The nature of the associations between $\mathrm{CMBs}$ and cognitive performance was, however, variable and not necessarily independent. While the presence of CMBs was predictive of progression from MCI to dementia in the cohort of Kirsch et al, ${ }^{13}$ this association did not persist when adjusting for age. We found no association between cognitive decline at 18-month follow-up and CMB burden or location at baseline.

Several reasons may explain this clinicoradiologic dissociation. The low number of microbleeds in this community-based sample may prevent establishing valid correlations with clinical variables. Such correlations may become obvious at later time points at further follow-up; the absence of follow-up imaging constitutes one of the limitations of the present investigation. Similarly, the short clinical follow-up interval may have masked potential associations. Kirsch et $\mathrm{al}^{13}$ noted that during the 50 month follow-up of their study, only $5 \%$ of the subjects initially classified as healthy controls progressed to MCI or dementia. In the cohort of Miwa et al, ${ }^{34} 8 \%$ of subjects developed dementia during a median follow-up of 7.5 years. Most of the prior studies did not investigate very early cognitive decline longitudinally. While $26 \%$ of controls in the present study showed deteriorating performance in an 18-month period, the investigated changes may have been too subtle, leading to the absence of an association with $\mathrm{CMB}$ observed here. In fact, we cannot formally exclude cognitive restoration possibly occurring at later time points in some of our subjects with dCON. One could speculate that a more prominent decline at later follow-up could allow identifying a cognitive impact of CMBs. However, this is unlikely because no difference in $\mathrm{CMB}$ prevalence was found between subjects with MCI with stable and deteriorating conditions in a prior study. ${ }^{36}$

Alternatively, structural damage reflected by isolated CMBs may not be important enough to impair clinically apparent locally associated functions, in contrast to the larger number of CMBs in vascular dementia and cerebral amyloid angiopathy (and Alzheimer disease). ${ }^{1,3,4}$

In contrast to $\mathrm{CMB}$, there has been rising interest in the correlation of declining cognitive function and another possible marker of small (and large) vessel disease in dementia, cortical microinfarcts. This entity consists of lesions barely visible at conventional imaging but demonstrated at pathology and 7T MR imaging, with the lesions visible on imaging (especially at $3 \mathrm{~T}$ ) representing only a small fraction of the actual lesional burden. ${ }^{37}$ Future radiologic studies with new-generation MRIs may lead to better insight into the deleterious effects of widely disseminated microvascular changes in advanced age.

\section{CONCLUSIONS}

Ultimately, in this large extensively tested cohort of subjects with MCI and controls having undergone MR imaging at 3T with a SWI sequence, there was no group-level difference in microbleed prevalence or distribution or a correlation with neuropsychological test results.

Disclosures: Sven Haller-RELATED: Grant: Swiss National Foundation Grant SNF 3200B0-1161193 and SPUM 33CM30-124111. * Money paid to the institution.

\section{REFERENCES}

1. Greenberg SM, Vernooij MW, Cordonnier C, et al; Microbleed Study Group. Cerebral microbleeds: a guide to detection and interpretation. Lancet Neurol 2009;8:165-74 CrossRef Medline

2. Fazekas F, Kleinert R, Roob G, et al. Histopathologic analysis of foci of signal loss on gradient-echo $\mathrm{T} 2^{\star}$-weighted MR images in patients with spontaneous intracerebral hemorrhage: evidence of microangiopathy-related microbleeds. AJNR Am J Neuroradiol 1999;20: 637-42 Medline

3. Cordonnier C, van der Flier WM, Sluimer JD, et al. Prevalence and severity of microbleeds in a memory clinic setting. Neurology 2006; 66:1356-60 CrossRef Medline

4. Vernooij MW, van der Lugt A, Ikram MA, et al. Prevalence and risk factors of cerebral microbleeds: the Rotterdam Scan Study. Neurology 2008;70:1208-14 CrossRef Medline

5. Sveinbjornsdottir S, Sigurdsson S, Aspelund T, et al. Cerebral microbleeds in the population based AGES-Reykjavik study: prevalence and location. J Neurol Neurosurg Psychiatry 2008;79:1002-06 CrossRef Medline

6. Schmidt R, Berghold A, Jokinen $\mathrm{H}$, et al. White matter lesion progression in LADIS: frequency, clinical effects, and sample size calculations. Stroke 2012;43:2643-47 CrossRef Medline

7. Del Brutto VJ, Zambrano M, Mera RM, et al. Population-based study of cerebral microbleeds in stroke-free older adults living in Rural Ecuador: the Atahualpa Project. Stroke 2015;46:1984-86 CrossRef Medline

8. Loitfelder M, Seiler S, Schwingenschuh P, et al. Cerebral microbleeds: a review. Panminerva Med 2012;54:149-60 Medline Medline

9. Park JH, Seo SW, Kim C, et al. Pathogenesis of cerebral microbleeds: in vivo imaging of amyloid and subcortical ischemic small vessel disease in 226 individuals with cognitive impairment. Ann Neurol 2013;73:584-93 CrossRef Medline

10. Nagasawa J, Kiyozaka T, Ikeda K. Prevalence and clinicoradiological analyses of patients with Alzheimer disease coexisting multiple microbleeds. J Stroke Cerebrovasc Dis 2014;23:2444-49 CrossRef Medline

11. Yakushiji Y, Yokota C, Yamada N, et al. Clinical characteristics by topographical distribution of brain microbleeds, with a particular emphasis on diffuse microbleeds. J Stroke Cerebrovasc Dis 2011;20: 214-21 CrossRef Medline

12. Qiu C, Cotch MF, Sigurdsson S, et al. Cerebral microbleeds, retinopathy, and dementia: the AGES-Reykjavik Study. Neurology 2010;75: 2221-28 CrossRef Medline

13. Kirsch W, McAuley G, Holshouser B, et al. Serial susceptibility weighted MRI measures brain iron and microbleeds in dementia. J Alzheimers Dis 2009;17:599-609 Medline

14. Uetani H, Hirai T, Hashimoto M, et al. Prevalence and topography of small hypointense foci suggesting microbleeds on $3 \mathrm{~T}$ susceptibility-weighted imaging in various types of dementia. AJNR Am J Neuroradiol 2013;34:984-89 CrossRef Medline

15. Hilal S, Saini M, Tan CS, et al. Cerebral microbleeds and cognition: the epidemiology of dementia in Singapore study. Alzheimer Dis Assoc Disord 2014;28:106-12 CrossRef Medline

16. Kester MI, Goos JD, Teunissen CE, et al. Associations between cerebral small-vessel disease and Alzheimer disease pathology as mea- 
sured by cerebrospinal fluid biomarkers. JAMA Neurol 2014;71: 855-62 CrossRef Medline

17. Gregoire SM, Smith K, Jäger HR, et al. Cerebral microbleeds and long-term cognitive outcome: longitudinal cohort study of stroke clinic patients. Cerebrovasc Dis 2012;33:430 -35 CrossRef Medline

18. van der Flier WM. Clinical aspects of microbleeds in Alzheimer's disease. J Neurol Sci 2012;322:56-58 CrossRef Medline

19. Heringa SM, Reijmer YD, Leemans A, et al; Utrecht Vascular Cognitive Impairment (VCI) Study Group. Multiple microbleeds are related to cerebral network disruptions in patients with early Alzheimer's disease. J Alzheimers Dis 2014;38:211-21 CrossRef Medline

20. Park JH, Seo SW, Kim C, et al. Effects of cerebrovascular disease and amyloid beta burden on cognition in subjects with subcortical vascular cognitive impairment. Neurobiol Aging 2014;35:254-60 CrossRef Medline

21. Patel B, Lawrence AJ, Chung AW, et al. Cerebral microbleeds and cognition in patients with symptomatic small vessel disease. Stroke 2013;44:356-61 CrossRef Medline

22. Lei C, Lin S, Tao W, et al. Association between cerebral microbleeds and cognitive function: a systematic review. J Neurol Neurosurg Psychiatry 2013;84:693-97 CrossRef Medline

23. Yates PA, Desmond PM, Phal PM, et al; AIBL Research Group. Incidence of cerebral microbleeds in preclinical Alzheimer disease. Neurology 2014;82:1266-73 CrossRef Medline

24. Poels MM, Ikram MA, van der Lugt A, et al. Cerebral microbleeds are associated with worse cognitive function: the Rotterdam Scan Study. Neurology 2012;78:326-33 CrossRef Medline

25. Hughes CP, Berg L, Danziger WL, et al. A new clinical scale for the staging of dementia. Br J Psychiatry 1982;140:566-72 CrossRef Medline

26. Petersen RC. Mild cognitive impairment as a diagnostic entity. J Intern Med 2004;256:183-94 CrossRef Medline

27. Deiber MP, Meziane HB, Hasler R, et al. Attention and working memory-related EEG markers of subtle cognitive deterioration in healthy elderly individuals. J Alzheimers Dis 2015;47:335-49 CrossRef Medline
28. Fazekas F, Chawluk JB, Alavi A, et al. MR signal abnormalities at $\mathbf{1 . 5}$ $T$ in Alzheimer's dementia and normal aging. AJR Am J Roentgenol 1987;149:351-56 CrossRef Medline

29. Jeerakathil T, Wolf PA, Beiser A, et al. Cerebral microbleeds: prevalence and associations with cardiovascular risk factors in the Framingham Study. Stroke 2004;35:1831-35 CrossRef Medline

30. Nandigam RN, Viswanathan A, Delgado P, et al. MR imaging detection of cerebral microbleeds: effect of susceptibility-weighted imaging, section thickness, and field strength. AJNR Am J Neuroradiol 2009;30:338-43 Medline

31. Goos JD, van der Flier WM, Knol DL, et al. Clinical relevance of improved microbleed detection by susceptibility-weighted magnetic resonance imaging. Stroke 2011;42:1894-900 CrossRef Medline

32. Shams S, Martola J, Cavallin L, et al. SWI or T2*: which MRI sequence to use in the detection of cerebral microbleeds? The Karolinska Imaging Dementia Study. AJNR Am J Neuroradiol 2015;36: 1089-95 CrossRef Medline

33. Ayaz M, Boikov AS, Haacke EM, et al. Imaging cerebral microbleeds using susceptibility weighted imaging: one step toward detecting vascular dementia. J Magn Reson Imaging 2010;31:142-48 CrossRef Medline

34. Miwa K, Tanaka M, Okazaki S, et al. Multiple or mixed cerebral microbleeds and dementia in patients with vascular risk factors. Neurology 2014;83:646-53 CrossRef Medline

35. Chiang GC, Cruz Hernandez JC, Kantarci K, et al. Cerebral microbleeds, CSF p-tau, and cognitive decline: significance of anatomic distribution. AJNR Am J Neuroradiol 2015;36:1635-41 CrossRef Medline

36. Haller S, Bartsch A, Nguyen D, et al. Cerebral microhemorrhage and iron deposition in mild cognitive impairment: susceptibilityweighted MR imaging assessment. Radiology 2010;257:764-73 CrossRef Medline

37. van Veluw SJ, Hilal S, Kuijf HJ, et al. Cortical microinfarcts on 3T MRI: clinical correlates in memory-clinic patients. Alzheimers Dement 2015;11:1500-09 CrossRef Medline 